Supporting Information for "Octahedral Non-Heme Non-Oxo Fe(IV) Species Stabilized by a Redox-Innocent $N$-Methylated Cyclam-Acetate Ligand"

John F. Berry, Eckhard Bill, Eberhard Bothe, Thomas Weyhermüller, and Karl Wieghardt*

\title{
Experimental
}

The ligand 1,4,8,11-tetraazacyclotetradecane-1-acetic acid tetrahydrochloride was synthesized according to published methods. ${ }^{1}\left[\mathrm{NEt}_{4}\right]\left[\mathrm{FeCl}_{4}\right]$ was prepared similarly to the tetrabutylammonium salt. $^{2}$<smiles>CN1CCCN(C)CCN(CC(=O)O)CCCN(C)CC1</smiles>

\section{4,8,11-Trimethyl-1,4,8,11-tetraazacyclotetradecane-1-acetic Acid Tetrahydrochloride}

(Me 3 cyclam-acetic acid tetrahydrochloride). A stirred solution of 1,4,8,11-

tetraazacyclotetradecane-1-acetic acid tetrahydrochloride $(4.23 \mathrm{~g}, 10.5 \mathrm{mmol})$ in $25 \mathrm{~mL}$ of $90 \%$ formic acid and $10 \mathrm{~mL}$ of $35 \%$ formaldehyde was heated to $100{ }^{\circ} \mathrm{C}$ for $24 \mathrm{~h}$. The resulting light brown solution was cooled to room temperature, and the solvents were removed in vacuo. To the resulting brown residue, $25 \mathrm{~mL}$ of $37 \%$ hydrochloric acid was added. The product was precipitated by addition of absolute ethanol, collected by filtration, and washed with ethanol and diethyl ether. Yield: $3.35 \mathrm{~g}$, 72\%. IR (KBr, cm $\left.{ }^{-1}\right): 3417$, vs, br, $2961 \mathrm{~s}, 2633$ vs, $2483 \mathrm{~s}, 1743 \mathrm{~s}(\mathrm{C}=\mathrm{O}), 1628 \mathrm{~m}, 1489 \mathrm{~s}, 1425 \mathrm{~s}$, 1380 m, 1347 w, 1197 m, 1148 w, 1056 w, 998 w, 972 w, 904 w, 778 w, 745 w, 669 w, 576 m, 546 m. ${ }^{1} \mathrm{H}$ NMR $\left(\mathrm{D}_{2} \mathrm{O}, 400 \mathrm{MHz}, \delta, \mathrm{ppm}\right.$ - peak assignments were made with the aid of a COSY spectrum): $3.673 \mathrm{~s}\left(4 \mathrm{H}, \mathrm{CH}_{2} \mathrm{CH}_{2}\right), 3.542 \mathrm{~s}\left(1 \mathrm{H}, \mathrm{CH}_{2} \mathrm{COOH}\right), 3.532 \mathrm{~s}\left(1 \mathrm{H}, \mathrm{CH}_{2} \mathrm{COOH}\right), 3.434-3.354 \mathrm{~m}(8 \mathrm{H}$, $\left.\mathrm{CH}_{2} \mathrm{CH}_{2} \mathrm{CH}_{2}, \mathrm{CH}_{2} \mathrm{CH}_{2} \mathrm{CH}_{2}, \mathrm{CH}_{2} \mathrm{CH}_{2}\right), 3.112-3.101 \mathrm{~m}$, br, $\left(2 \mathrm{H}, \mathrm{CH}_{2} \mathrm{CH}_{2}\right), 2.939-2.875 \mathrm{~m},(11 \mathrm{H}, 3 \mathrm{x}$ $\left.\mathrm{CH}_{3}, \mathrm{CH}_{2} \mathrm{CH}_{2} \mathrm{CH}_{2}\right), 2.244 \mathrm{q}\left(J=7.45 \mathrm{~Hz}, 2 \mathrm{H}, \mathrm{CH}_{2} \mathrm{CH}_{2} \mathrm{CH}_{2}\right), 1.940 \mathrm{q}\left(J=7.2 \mathrm{~Hz}, 2 \mathrm{H}, \mathrm{CH}_{2} \mathrm{CH}_{2} \mathrm{CH}_{2}\right)$. ES Mass spectrum (m/z, amu): $300(\mathrm{M}-4 \mathrm{HCl})^{+}$. Analysis calcd. For $\mathrm{C}_{15} \mathrm{H}_{42} \mathrm{~N}_{4} \mathrm{O}_{7} \mathrm{Cl}_{4}\left(\mathrm{M} \cdot 3 \mathrm{H}_{2} \mathrm{O}\right): \mathrm{C}$ 36.01, H 8.46, N 11.20\%. Found: C 35.60, H 8.47, N 11.10\%. 
$\left[\left(\mathbf{M e}_{3}\right.\right.$ cyclam-acetate $\left.) \mathbf{F e N}_{3}\right] \mathbf{P F}_{6}$ To a suspension of $\mathrm{Me}_{3}$ cyclam-acetic acid tetrahydrochloride $(0.400 \mathrm{~g}, 0.897 \mathrm{mmol})$ in $30 \mathrm{~mL}$ of acetonitrile was added $500 \mu \mathrm{L}$ (1.79 mmol) of triethylamine. After stirring for $1 \mathrm{~min}$, a clear solution resulted. To this solution was added a solution of $\left[\mathrm{NEt}_{4}\right]\left[\mathrm{FeCl}_{4}\right](0.600 \mathrm{~g}, 1.79 \mathrm{mmol})$ in $15 \mathrm{~mL}$ of acetonitrile, resulting in an immediate color change to dark orange. The mixture was heated at $90{ }^{\circ} \mathrm{C}$ for two hours, and then a second quantity of $200 \mu \mathrm{L}$ of triethylamine was added. The dark red mixture was heated again to $90{ }^{\circ} \mathrm{C}$ for two hours and then allowed to cool to room temperature. The solvent was removed by rotary evaporation, and the residue was washed with diethyl ether $(2 \times 20 \mathrm{~mL})$, cold ethanol $(3 \times 20 \mathrm{~mL})$, and again with diethyl ether $(10$ $\mathrm{mL}$ ). The resulting dark red solid was dissolved in $10 \mathrm{~mL}$ of $\mathrm{MeOH}$, and $\mathrm{NaN}_{3}$ (244 mg, $3.75 \mathrm{mmol}$ ) was added, resulting in a deep red mixture. To this mixture was added $\mathrm{KPF}_{6}(0.416 \mathrm{~g}, 2.26 \mathrm{mmol})$ dissolved in $5 \mathrm{~mL}$ of water, and the resulting mixture was stirred for $6 \mathrm{~h}$, when a copious dark red precipitate was observed. The solid was collected by filtration, washed with $\mathrm{Et}_{2} \mathrm{O}$, and dried in air to yield $240 \mathrm{mg}$ of the crude product, with iron oxide present as a contaminant. This red solid was extracted with $\mathrm{MeCN}$ to give a brilliant red solution, which was allowed to slowly evaporate in the dark yielding a crop of red crystals of $\left[\left(\mathrm{Me}_{3}\right.\right.$ cyclam-acetate $\left.) \mathrm{FeN}_{3}\right] \mathrm{PF}_{6}$. Yield: $125 \mathrm{mg}, 26 \%$. IR $(\mathrm{KBr}$, $\left.\mathrm{cm}^{-1}\right): 3432 \mathrm{~s}$, br, 2090 vs $\left(\mathrm{N}_{3}\right), 1671 \mathrm{~s}(\mathrm{C}=\mathrm{O}), 1465 \mathrm{~m}, 1367 \mathrm{~m}, 1296 \mathrm{~m}, 1023 \mathrm{w}, 968 \mathrm{w}, 956 \mathrm{w}, 916$ w, $844 \mathrm{~s}\left(\mathrm{PF}_{6}\right), 744 \mathrm{w}, 558 \mathrm{~m}$. ESI ${ }^{+}$Mass spectrum (m/z, amu): $397.2\left(\mathrm{M}-\mathrm{PF}_{6}\right)^{+}$. Analysis calcd. for $\mathrm{C}_{15} \mathrm{H}_{31} \mathrm{O}_{2} \mathrm{~N}_{7} \mathrm{FePF}_{6}$ : C 33.22, H 5.76, N 18.08\%. Found: C 33.58, H 5.78, N 17.00\%.

$\left[\mathbf{N E t}_{4}\right]\left[{ }^{57} \mathbf{F e C l}_{4}\right]$ A sample of ${ }^{57} \mathrm{Fe}$ foil $(32 \mathrm{mg}, 0.56 \mathrm{mmol})$ was dissolved in hot concentrated $\mathrm{HCl}$ (over Pt foil, to expedite the process). The resulting yellow solution was cooled to room temperature, and the solvent was removed in a rotary evaporater yielding an orange solid residue. This was dissolved in a minimal amount of $\mathrm{EtOH}(\sim 1 \mathrm{~mL})$, and added to a solution of excess $\mathrm{NEt}_{4} \mathrm{Cl}$ which was also dissolved in a minimal amount of EtOH. Upon mixing, a bright yellow precipitate appeared, and the mixture was stirred for $\sim 30 \mathrm{~min}$ to ensure complete reaction. The solid was collected by filtration, washed with $\mathrm{Et}_{2} \mathrm{O}$, and dried in air. Yield: $154 \mathrm{mg}, 83 \%$. Isotopically enriched compounds were prepared using a 40:60 w/w ratio of $\left[\mathrm{NEt}_{4}\right]\left[{ }^{57} \mathrm{FeCl}_{4}\right]$ and normal $\left[\mathrm{NEt}_{4}\right]\left[\mathrm{FeCl}_{4}\right]$. 


\section{References.}

(1) Studer, M.; Kaden, T. A. Helv. Chim. Acta 1986, 69, 2081.

(2) Grapperhaus, C. A.; Li, M.; Patra, A. K.; Poturovic, S.; Kozlowski, P. M.; Zgierski, M. Z.; Mashuta, M. S. Inorg. Chem. 2003, 42, 4382. 


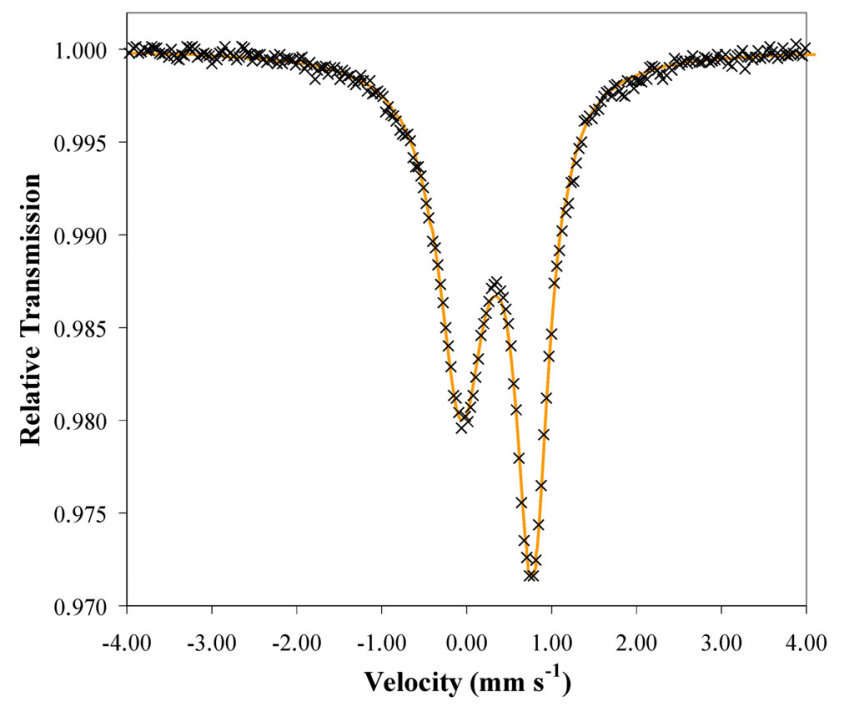

Figure S1. Mössbauer spectrum of $1\left(40 \%\right.$ enriched with $\left.{ }^{57} \mathrm{Fe}\right)$ in frozen acetonitrile solution at 200 K. 


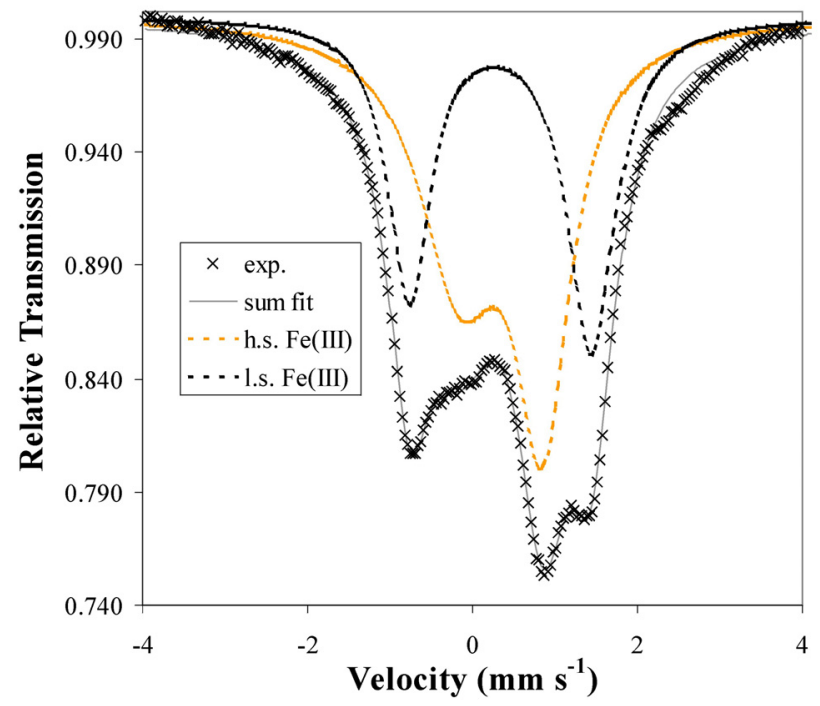

Figure S2. Mössbauer spectrum of $1\left(40 \%\right.$ enriched with $\left.{ }^{57} \mathrm{Fe}\right)$ in acetonitrile solution at $80 \mathrm{~K}$.

Simulation with $60 \%$ high-spin and $40 \%$ low-spin yields the following parameters: $\delta_{\mathrm{HS}}=0.35 \mathrm{~mm}$ $\mathrm{s}^{-1}, \Delta \mathrm{E}_{\mathrm{QHS}}=1.00 \mathrm{~mm} \mathrm{~s}^{-1} ; \delta_{\mathrm{LS}}=0.33 \mathrm{~mm} \mathrm{~s}^{-1}, \Delta \mathrm{E}_{\mathrm{QLS}}=2.21 \mathrm{~mm} \mathrm{~s}^{-1}$. 


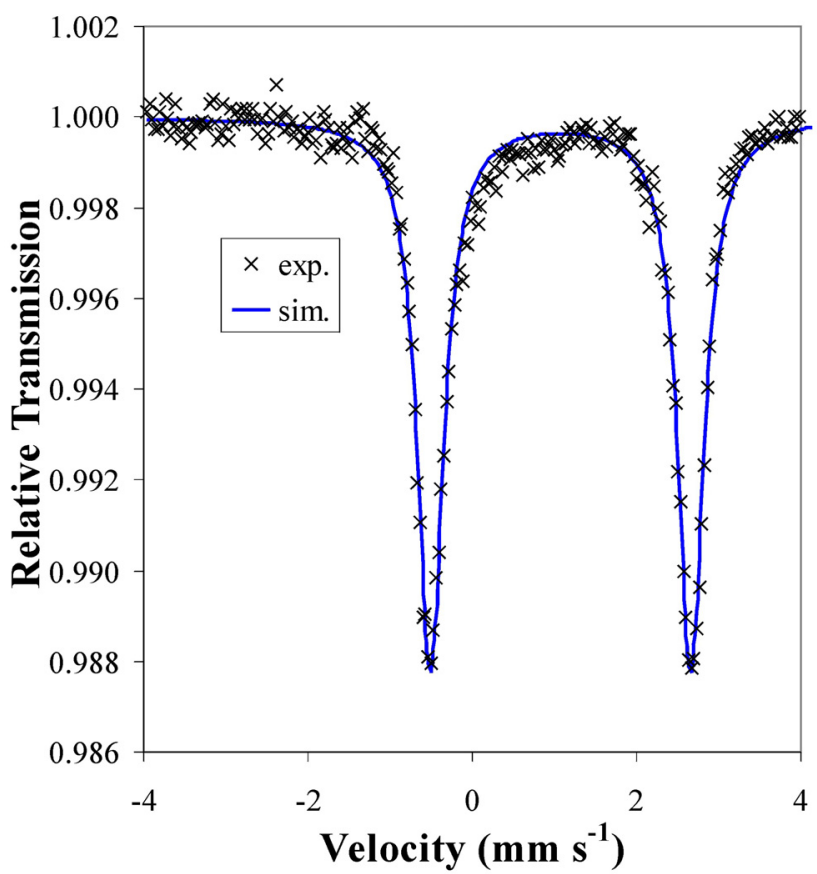

Figure S3. Mössbauer spectrum of electrochemically generated 1red (40\% enriched with $\left.{ }^{57} \mathrm{Fe}\right)$ in frozen acetonitrile solution at $80 \mathrm{~K}$. Simulation yields the following parameters: $\delta=1.08 \mathrm{~mm} \mathrm{~s}^{-1}, \Delta \mathrm{E}_{\mathrm{Q}}$ $=3.17 \mathrm{~mm} \mathrm{~s}^{-1}$. 


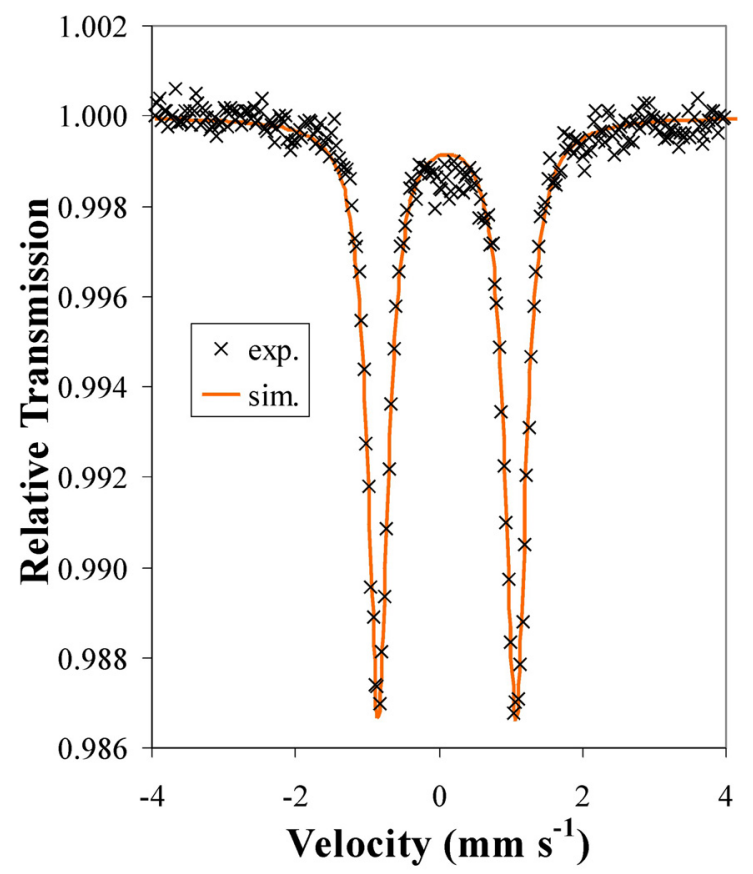

Figure S4. Mössbauer spectrum of electrochemically generated 1ox $\left(40 \%\right.$ enriched with $\left.{ }^{57} \mathrm{Fe}\right)$ in frozen acetonitrile solution at $80 \mathrm{~K}$. The following parameters were obtained from simulation: $\delta=$ $0.11 \mathrm{~mm} \mathrm{~s}^{-1}, \Delta \mathrm{E}_{\mathrm{Q}}=1.92 \mathrm{~mm} \mathrm{~s}^{-1}$. 


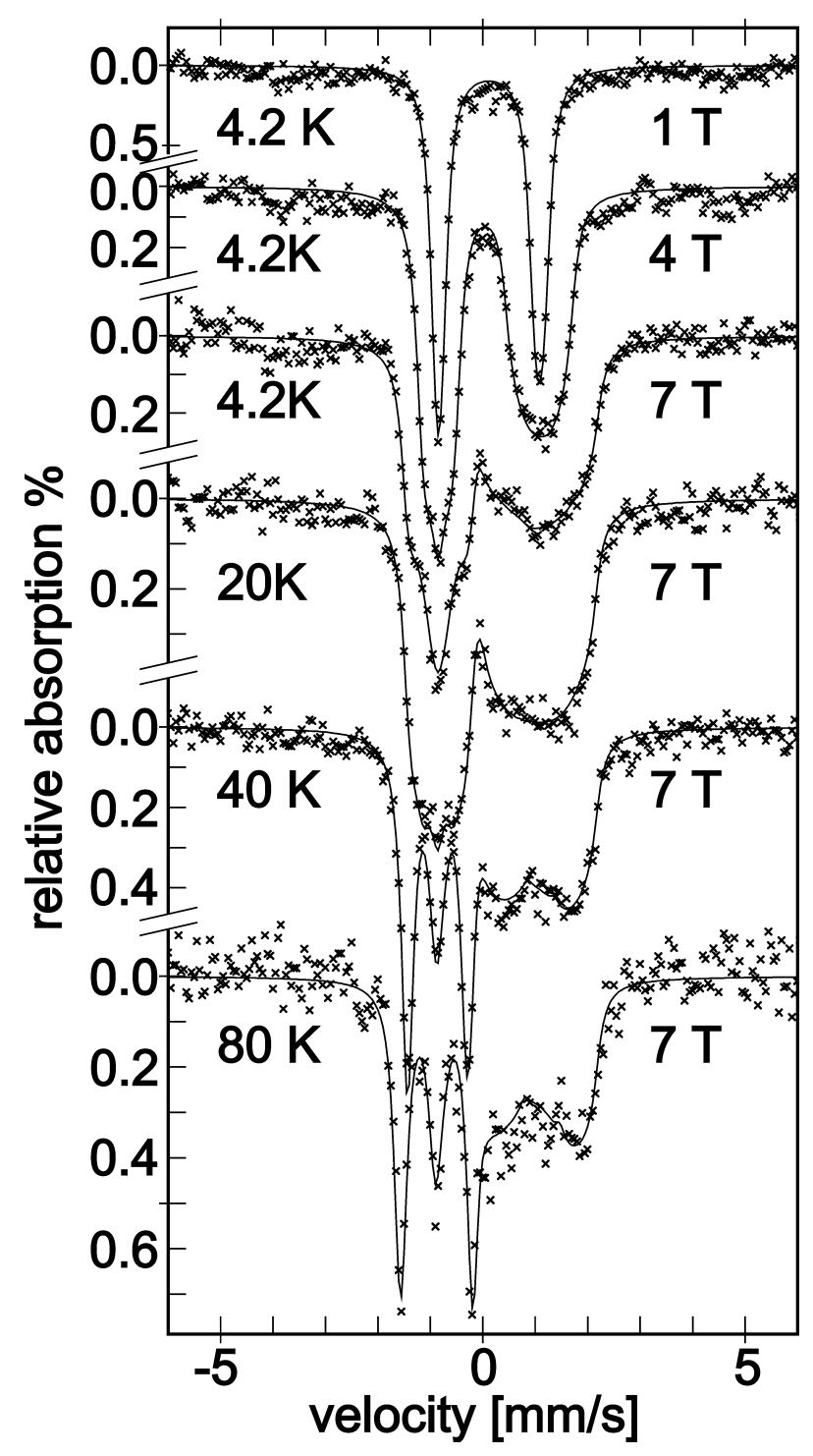

Figure S5. Magnetic Mössbauer spectra of 1ox at fields of 1, 4, and $7 \mathrm{~T}$ applied perpendicular to the $\gamma$ rays and temperatures of $4.2,20,40$, and $80 \mathrm{~K}$. The solid lines represent spin-Hamiltonian simulations assuming an $S=1$ ground state. The following parameters were obtained from the fitting procedure: $\delta=0.12 \mathrm{~mm} \mathrm{~s}^{-1}, \Delta \mathrm{E}_{\mathrm{Q}}=1.92$ $\mathrm{mm} \mathrm{s}^{-1}, \eta=0.1, D=23.7 \mathrm{~cm}^{-1}, E / D=0.02$ (fixed), $g_{x}=g_{y}=g_{z}=2.0$ (fixed), $A / g_{N} \beta_{N}=(-15.4,-17.8,-2.3 \mathrm{~T})$. Rotation angles between the zero-field splitting tensor and the electric field gradient tensor were not considered in the fit. Fits assuming $S=2$ are comparable in quality, but the refined $A$ values of $-4.8,-5.8$, and $0.0 \mathrm{~T}$ are physically unrealistic. 